\title{
Combination of Electroporation and DNA/Dendrimer Complexes Enhances Gene Transfer into Murine Cardiac Transplants
}

\author{
Yinong Wang ${ }^{a, 1}$, Yalai Bai ${ }^{a, 1}$, Christopher Price ${ }^{a}$, \\ Peter Borosa, Lihui Qina , Anna U. Bielinskab, \\ Jolanta F. Kukowska-Latallob, \\ James R. Baker Jr'b \\ and Jonathan S. Bromberg ${ }^{a, *}$ \\ a Institute for Gene Therapy and Molecular Medicine and \\ the Recanati/Miller Transplantation Institute, Mount Sinai \\ School of Medicine, New York, NY 10029-6574, USA \\ ${ }^{b}$ Center for Biologic Nanotechnology, The University of \\ Michigan, Ann Arbor, MI 48105, USA \\ * Corresponding author: Jonathan S. Bromberg. \\ jon.bromberg@mountsinai.org
}

Electroporation is a new gene delivery method to increase gene transfer and expression in vivo. Starburst polyamidoamine dendrimers have been demonstrated to augment gene expression in vitro and in vivo. We hypothesized that the combination of electroporation and dendrimer could enhance the gene transfer and gene expression in cardiac transplants. After immersion in DNA/dendrimer complexes or intracoronary transfer of DNA/dendrimer complexes, both nonvascularized and vascularized syngeneic cardiac grafts, respectively, were subjected to serial electrical pulses before transplantation. $\beta$-Galactosidase reporter gene expression in the graft was determined by X-Gal staining. Gene expression was enhanced 10 - to 45 -fold in grafts immersed in DNA/dendrimer complexes, or after intracoronary transfer of DNA/dendrimer complexes, and subjected to 20 square wave $25-\mathrm{ms}$ pulses with a strength of $200 \mathrm{~V} / \mathrm{cm}$. The combination of electroporation and DNA/dendrimer complexes may provide a novel approach to enhance gene transfer and gene expression ex vivo.

Key words: Dendrimer, electroporation, gene transfer, transplantation

Received 11 April 2001, revised and accepted for publication 21 June 2001

\section{Introduction}

Efficient delivery of target genes into cardiovascular tissues may provide a new therapeutic modality for the treatment of

\footnotetext{
${ }^{1}$ Present address: Department of Surgery (Cardiothoracic), Yale University
} School of Medicine, 333 Cedar Street, 121 FMB, New Haven, CT 06510. various heart diseases and heart allograft rejection. Various strategies have been investigated to transfer genes to organs, and many studies have demonstrated that a variety of techniques using plasmid or viral vectors can deliver and express exogenous genes to cardiovascular tissues (1-14). In 1982, Neumann et al. (15) demonstrated that in vitro electroporation of cells in the presence of plasmid DNA resulted in DNA transfer and expression. Since then, this method has been widely used for gene delivery to increase gene transfer and expression in vitro and, more recently, in vivo (16-24). The mechanism of electroporation-mediated gene transfer is thought to be based on formation of membrane pores followed by DNA electrophoresis into the cells (25). Muscle, as an electrically conductive organ, may be particularly amenable to permeation by electrical shocks. Indeed, electroporation to skeletal muscle is very effective (21-23), and the feasibility of its use in embryonic chick myocardium has been demonstrated (19).

A class of synthetic, highly branched, spherical, polyamidoamine (PAMAM) dendrimer polymers has a structural advantage for gene transfer. These molecules are uniform in size, have a high density of charged primary amino groups restricted to the surface, are highly soluble, and are stable in aqueous solution. Recent studies have shown that Starburst dendrimers are nonimmunogenic and can mediate and enhance gene transfer and gene expression in vitro and in vivo (26-29). Our recent studies demonstrated that dendrimer significantly increased the efficiency of plasmid-mediated gene transfer and expression in murine heterotopic, nonvascularized and vascularized cardiac grafts. Direct injection or intracoronary delivery of DNA/dendrimer complexes constituted with the fifth generation of ethylenediamine (EDA) core dendrimer (G5EDA) increased the efficiency of plasmid gene transfer $(1,29)$. In this study, we investigated the combination of electroporation and DNA/dendrimer complexes to increase gene transfer efficiency and gene expression in both murine nonvascularized and vascularized cardiac transplantation model.

\section{Methods}

\section{Materials}

C57BL/6J mice were purchased from the Jackson Laboratories (Bar Harbor, ME). Plasmid source and preparation, dendrimer source and preparation, and histologic procedures have been described in detail previously $(1,29)$. 


\section{Gene transfection}

The plasmid pMP6A- $\beta$-gal, encoding $\beta$-galactosidase ( $\beta$-Gal) under the control of a CMVie promoter, was mixed with the fifth generation of ethylenediamine core dendrimers in PBS to form complexes. For nonvascularized cardiac transplantation, the whole hearts were removed from neonatal C57BL/ 6 mice and individually placed in an electroporation cuvette ( $0.4 \mathrm{~cm}$ electrode gap) containing $100 \mu \mathrm{L}$ of cold DNA/dendrimer solution, or DNA alone, and subjected to electroporation with a conventional electroporation apparatus (Gene Pulser $^{\mathrm{TM}}$, BioRad, Hercules, CA). This apparatus delivers square wave pulses with a duration of $25 \mathrm{~ms}$ and variable voltage. The hearts were then transplanted subcutaneously to the ear pinnae of adult C57BL/6 recipients. Graft function and survival were evaluated by electrocardiography every other day.

For vascularized cardiac transplantation, the donor heart was arrested by infusion of $0.5 \mathrm{~mL}$ of University of Wisconsin (UW) solution into the inferior vena cava. The aortic root was flushed with $0.1 \mathrm{~mL}$ of UW solution to expel intracoronary blood thoroughly, and $0.2 \mathrm{~mL}$ of the DNA/dendrimer complexes (containing $20 \mu \mathrm{g}$ DNA plus $260 \mu \mathrm{g}$ dendrimer) were then infused into the aortic root with a 30 -gauge needle. The heart was removed from the chest and placed into $200 \mathrm{~mL}$ UW solution in an electroporation cuvette $10.4 \mathrm{~cm}$ electrode gap). After electroporation, the heart was removed from the cuvette and implanted. The donor aorta and pulmonary artery were joined end-to-side to the recipient aorta and vena cava, respectively, using 10-0 nylon suture. After the completion of the anastomoses, the abdomen was closed with a single running suture to all layers. The total cold ischemic time, including incubation time, was $1 \mathrm{~h}$. The recipient mouse was then warmed for a few hours during recovery from anesthesia and had free access to water and food. The function of the transplanted hearts was assessed daily by abdominal palpation (29).

\section{Histology}

Transplanted hearts were obtained, frozen, and sectioned at $10 \mu \mathrm{m}$ for $\beta$-Gal determination by X-gal staining on postoperative day $7(1,29)$. For quantitative analysis of gene expression, the total number of cells positively staining for $\mathbf{X}$-gal was counted per section under magnification $(\times 40)$, and a mean value was calculated for five sections per graft, and two to four grafts per group. The overall mean values were determined for each group, and numbers are expressed as mean \pm standard deviation of the number of stained cells observed. The significance of the difference in gene expression for the groups was determined using Students' $t$-test. The level of significance was accepted as $p<0.05$.

\section{Results}

In the syngeneic, nonvascularized, cardiac transplants, we compared the combination of electroporation with either direct injection of DNA/dendrimer complexes into the graft or immersion of the graft in DNA/dendrimer complexes. The dose of DNA, the method of DNA/dendrimer complex delivery, number of electrical pulses, and volts $/ \mathrm{cm}(\mathrm{V} / \mathrm{cm})$ were all determined to be critical factors for efficient gene transfer. In our previous studies, we determined that $0.31 \mu \mathrm{g}$ DNA complexed with $10 \mu \mathrm{g}$ dendrimer (1:50 DNA:dendrimer charge ratio) and injected into the graft in a $10 \mu \mathrm{L}$ volume resulted in optimal gene expression $(1,29)$. The combination of electroporation (12 pulses, $200 \mathrm{~V} / \mathrm{cm}$ ) with intragraft injection of DNA/dendrimer complexes improved gene expression in this group several-fold (Figure 1, group 2 vs. group 1, p $<0.05)$. However, this was not better than electroporation plus direct injection of naked DNA without dendrimer (group 3), while naked DNA alone without electroporation resulted in predictably poor gene expression (group 4).

While the DNA:dendrimer charge ratio of $1: 50$, and $0.31 \mu \mathrm{g}$ of DNA injected into the graft were previously found to be optimal for nonvascularized grafts (1), the modality of electroporation allowed us to examine the alternative method of DNA delivery by immersing the graft in the vector during the treatments. Direct immersion in $100 \mu \mathrm{L}$ of DNA:dendrimer solution (1:50 charge ratio) plus electroporation resulted in markedly increased gene expression compared with direct injection plus electroporation (group 2 vs. 9, $p<0.01$ ). Further dose-response analysis showed that higher DNA doses, while holding the DNA:dendrimer charge ratio constant, could further improve gene expression (groups 6, 9 vs. $8, p<0.01$ ). This enhancement of gene expression clearly depended on both the presence of dendrimer (group 5 vs. 8, $p<0.01$ ) and electroporation (group 7 vs. 8, $p<0.01$ ). The evaluation of other variables demonstrated that 12 pulses resulted in improved reporter expression compared with five pulses (group 11 vs. $8, p<0.01$ ), and were equivalent to 20 pulses (groups 8 vs. 10, $p=N S$ ). Pulse strength was optimal at $200 \mathrm{~V} / \mathrm{cm}$ (groups 13 vs. 8, 12, p <0.01). Histologically, reporter gene expression was seen throughout the myocardium (Figure 2), suggesting that electroporation allowed access of the DNA to distant or deep cells and tissues. This histologic analysis did not reveal cardiac myocyte necrosis as a result of the in vitro electroporation treatments. Likewise, gross anatomic study also did not reveal any changes or abnormalities of the transplant site.

The combination of electroporation and dendrimer delivery of plasmid DNA was also studied in vascularized, syngeneic cardiac transplants. Our previous studies demonstrated that optimal gene transfer and expression with the dendrimerbased system for reporter genes in a vascularized graft occurred with intracoronary delivery of $20 \mu \mathrm{g}$ DNA plus $260 \mu \mathrm{g}$ dendrimer (1:20 charge ratio) plus $10^{-5} \mathrm{M}$ serotonin in the aortic flush solution (29). We first determined if vascularized cardiac graft function could recover if the grafts were exposed to the pulses of electroporation. Initial studies showed that graft function was recoverable and the hearts survived for the observation period of several weeks when 20 or fewer pulses, at $200 \mathrm{~V} / \mathrm{cm}$, were administered. A greater number of electric pulses and/or higher voltages lead to almost 100\% 
Wang et al.

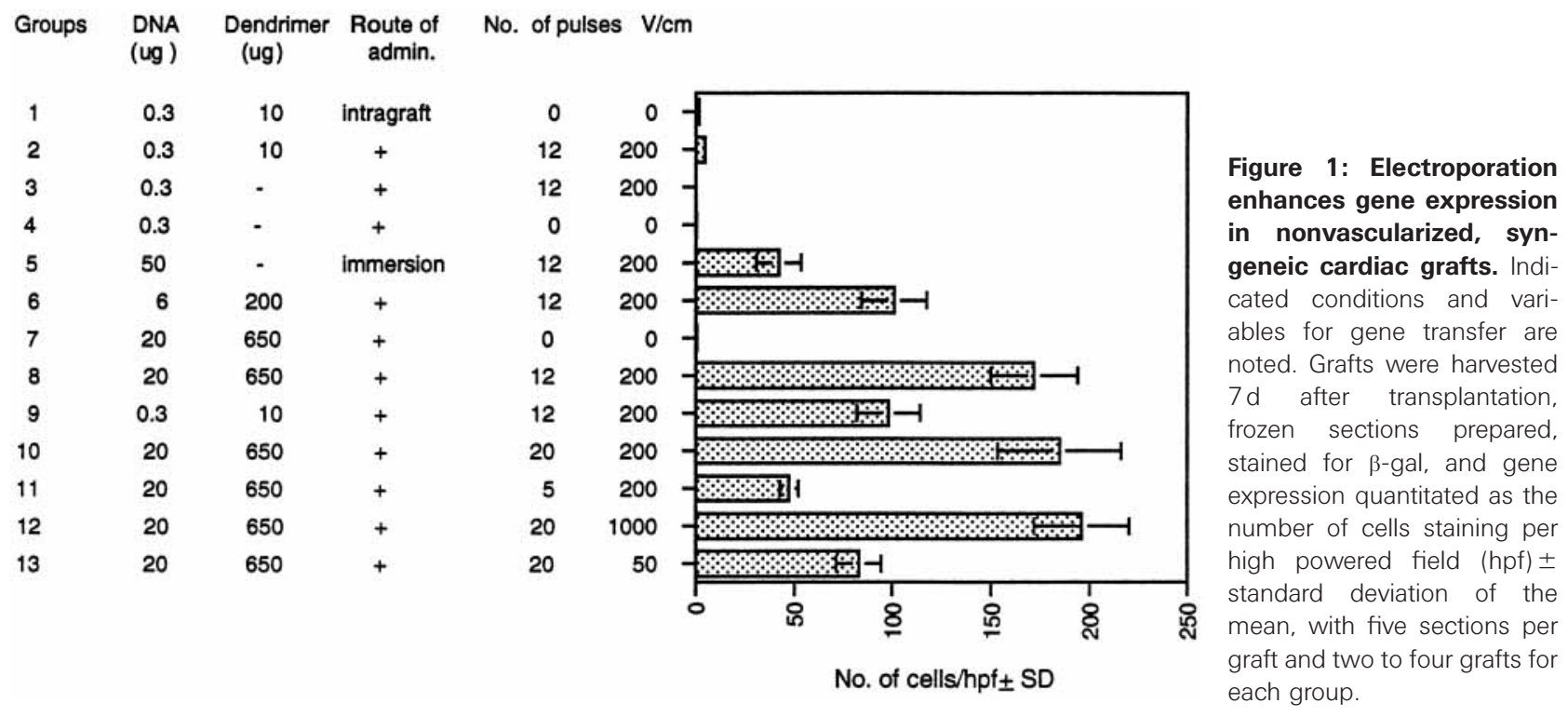

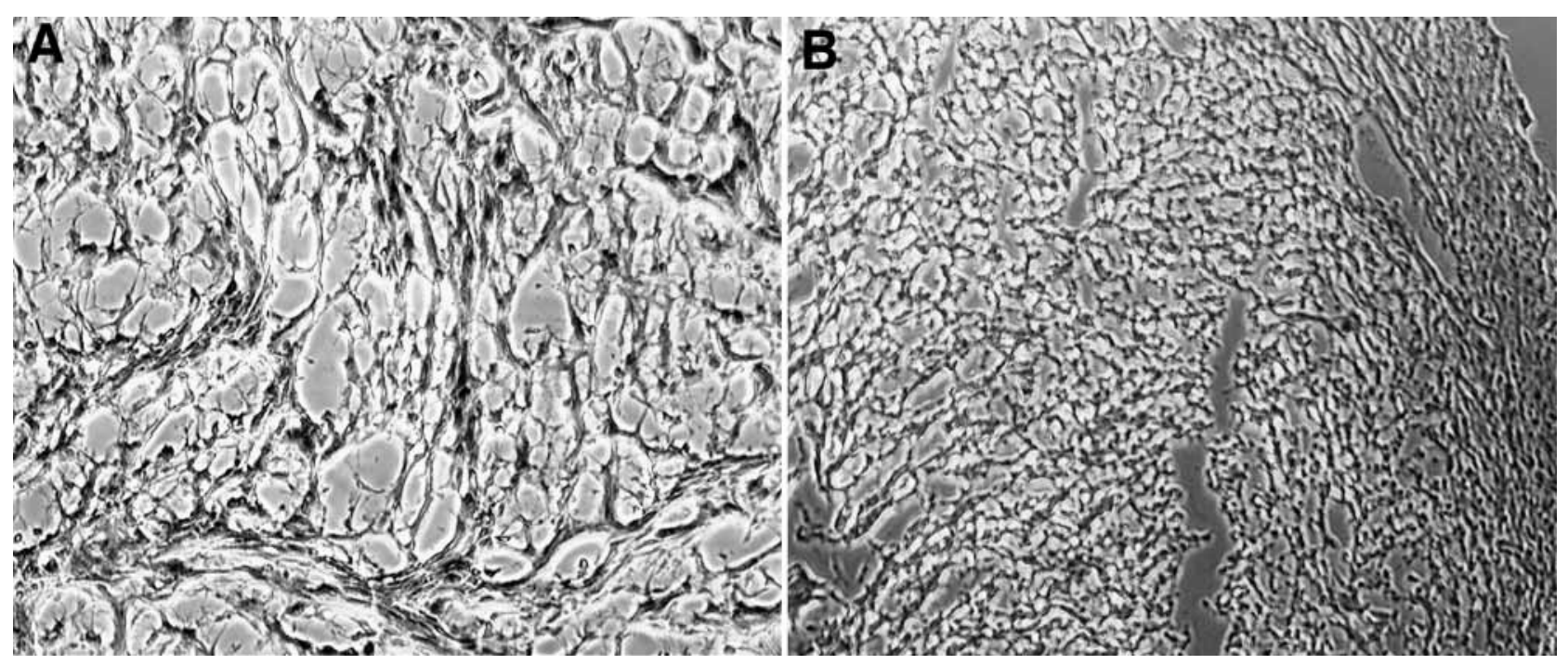

Figure 2: Enhanced expression of $\beta$-galactosidase in electroporated nonvascularized grafts. A. Graft treated as in group 12 , Figure 1. B. Graft treated as in group 4, Figure 1. Original magnification $\times 40$.

graft failure within $24 \mathrm{~h}$. At laparotomy, these grafts appeared necrotic and thrombosed. Therefore, the combination of electroporation and intracoronary delivery of DNA/dendrimer was examined, comparing five to 20 pulses and 50-200 V/cm for each pulse. The results in Figure 3 show that 20 pulses at $200 \mathrm{~V} / \mathrm{cm}$ provided optimal reported gene expression (group 4 vs. 1, 2, 3, p <0.01). Histologic and gross analysis did not show evidence of myonecrosis or inflammation (not shown).

\section{Discussion}

Gene transfer and gene therapy approaches for application to transplantation have received significant attention recently
(30-35). A variety of viral and nonviral vectors have successfully been used to introduce reporter genes into syngeneic grafts, and immunologically active genes into allografts, in order to suppress the local immune response and prolong allograft survival $(31-34)$. Numerous problems remain in the field of gene delivery, including effective ways to introduce genes into allografts. The direct injection of vectors into grafts limits the physical distribution of the vector $(4,5)$. Likewise, vascular perfusion of grafts with vectors likely limits distribution of the vector to the vascular endothelium and perhaps to some cells lying immediately underneath the vessels $(6,9)$. In addition, there remain problems of vector entry into cells, promoter activity and regulation, and innate and adaptive immune responses incited against the various types of vectors. The approach adopted here of electroporation may solve 


\section{Gene Transfer in Cardiac Transplants}

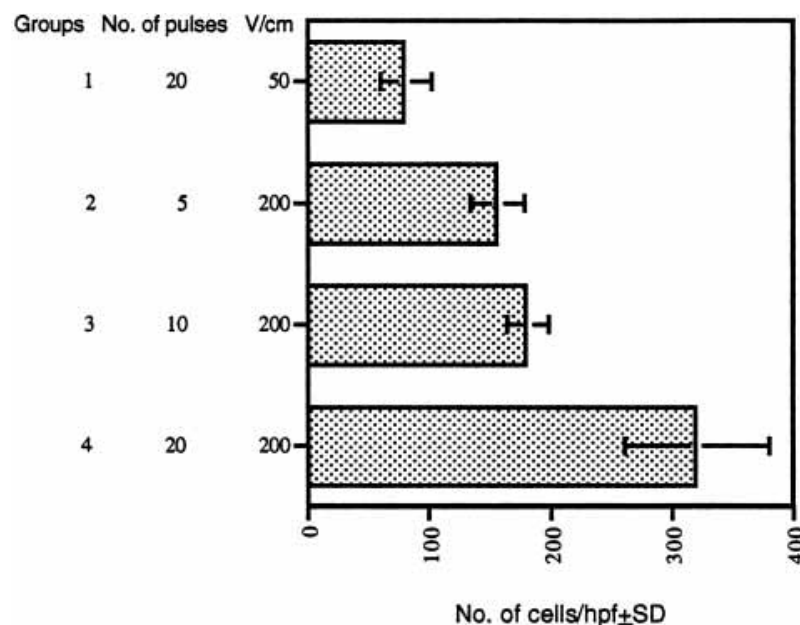

Figure 3: Electroporation enhances gene expression in vascularized syngeneic cardiac grafts. Indicated conditions and variables for gene transfer are noted, as in Figure 1.

some of these problems by allowing plasmid vectors to enter directly a multitude of cell types, including cells far from the vascular endothelium. Furthermore, the results here show that electroporation is compatible not only with naked plasmid DNA vectors, but also with plasmid DNA coupled to carriers such as the dendrimer. The dendrimer further enhances cell entry and may also protect the plasmid DNA from nucleases and further enhance translocation of the DNA from the cytoplasm to the nucleus of the cell (26-28).

While electroporation has been practiced for decades in vitro with single cells, it has only recently been applied in vivo for cell transfection (16-24). It has been shown to be particularly effective for skeletal myocyte gene transfer (21-23), possibly because of the intrinsic electrical properties of myocytes and muscle units (25). Previous reports have shown electroporation into muscle to be effective in achieving expression from reporter and other genes (21-23). This, however, is the first publication to show that viable mammalian myocardium may be successfully transfected with electroporation methods ex vivo and transplanted to achieve syngeneic graft survival. Given the extensive knowledge and experience with electrical stimulation of the myocardium, it can be anticipated that many more advances in the application of electroporation to the myocardium may be achieved in order to express genes relevant not only for allotransplantation, but also for atherosclerotic and ischemic disease.

It will be important to extend these observations to other aspects of gene transfer and gene therapy. Thus, it will be interesting to determine not only if electroporation facilitates the transfer of DNA into the cytoplasm, but also if it contributes to nucleic acid transport from cytoplasm to nucleus. Second, it will be important to understand how electroporation influences promoter function, and whether constitutive or regulatable promoters are influenced positively or negatively by the electroporation process. Third, since it is now clear that innate immune responses are a major influence in the interaction of viral and nonviral transfer vectors with cells, it will be important to determine how electroporation affects these inflammatory effects. Lastly, it will be important to examine the influence of immunoregulatory genes transferred via electroporation into allografts and determine if that influences the local and systemic immune responses and allograft survival.

\section{Acknowledgments}

This work was supported by the Baxter Extramural Grant Program, the Roche Organ Transplant Research Foundation, and NIH grant AI42840 (all to JSB). We thank Dr M. Philip for the pMP6A- $\beta$-gal plasmid.

\section{References}

1. Yinong Wang L, Qin Y, Bai AU et al. DNA/dendrimer complexes mediate gene transfer into murine cardiac transplants ex vivo. Mol Ther 2000; 2: 602-608.

2. Qin L, Chavin KD, Ding $Y$ et al. Multiple vectors effectively achieve gene transfer in a murine cardiac transplantation model: immunosuppression with TGF- $\beta 1$ or vIL-10. Transplantation 1995; 59: 809-816.

3. Acsadi G, Jiao S, Jani A et al. Direct gene transfer and expression into rat heart in vivo. The New Biologist 1991; 3: 71-81.

4. Lin H, Parmacek MS, Morle G, Bolling S, Leiden JM. Expression of recombinant genes in myocardium in vivo after direct injection of DNA. Circulation 1990; 82: 2217-2221.

5. Stratford-Perricaudet LD, Makeh I, Perricaudet M, Briand P. Expression of recombinant genes in myocardium in vivo after direct injection of DNA. J Clin Invest 1992; 90: 626-630.

6. Kass-Eisler A, Falck-Pedersen E, Alvira M et al. Quantitative determination of adenovirus-mediated gene delivery to rat cardiac myocytes in vitro and in vivo. Proc Natl Acad Sci USA 1993; 90: 11498-11502.

7. Wang J, Ma Y, Knechtle SJ. Adenovirus-mediated gene transfer into rat cardiac allografts. Transplantation 1996; 61: 1726-1729.

8. Donahue JK, Kikkawa K, Johns DC, Marban E, Lawrence JH. UItrarapid, highly efficient viral gene transfer to the heart. Proc Natl Acad Sci USA 1997; 94: 4664-4668.

9. Sawa Y, Kaneda Y, Bai H-Z et al. Efficient transfer of oligonucleotides and plasmid DNA into the whole heart through the coronary artery. Gene Therapy 1998; 5: 1472-1480.

10. Donahue JK, Kikkawa K, Thomas AD, Marban E, Lawrence JH. Acceleration of widespread adenoviral gene transfer to intact rabbit hearts by coronary perfusion with low calcium and serotonin. Gene Therapy 1998; 5: 630-634.

11. Mann MJ, Gibbons GH, Hutchinson $\mathrm{H}$ et al. Pressure-mediated oligonucleotide transfection of rat and human cardiovascular tissues. Proc Natl Acad Sci USA 1999; 96: 6411-6416.

12. Fromes $Y$, Salmon $A$, Wang $X$ et al. Gene delivery to the myocardium by intrapericardial injection. Gene Therapy 1999; 6: 683-688.

13. Svensson EC, Marshall DJ, Woodard K et al. Efficient and stable transduction of cardiomyocytes after intramyocardial injection or intracoronary perfusion with recombinant adeno-associated virus vectors. Circulation 1999; 99: 201-205.

14. Palasis M, Luo Z, Barry JJ, Walsh K. Analysis of adenoviral transport mechanism in the vessel wall and optimization of gene transfer using local delivery catheters. Hum Gene Ther 2000; 11: 237-246.

15. Neumann E, Schaefer-Ridder M, Wang Y, Hofschneider PH. Gene transfer into mouse myeloma cells by electroporation in high electric fields. EMBO J 1982; 1: 841-845.

16. Heller R, Jaroszeski M, Atkin A et al. In vivo gene electroinjection and expression in rat liver. FEBS Lett 1996; 389: 225-228. 
Wang et al.

17. Nishi T, Yoshizato K, Yamashiro S et al. High-efficiency in vivo gene transfer using intraarterial plasmid DNA injection following in vivo electroporation. Cancer Res 1996; 56: 1050-1055.

18. Suzuki T, Shin B, Fujikura K, Matsuzaki T, Takata K. Direct gene transfer into rat liver cells by in vivo electroporation. FEBS Lett 1998; 425: 436-440.

19. Harrison RL, Byrne BJ, Tung L. Electroporation-mediated gene transfer in cardiac tissue. FEBS Lett 1998; 435: 1-5.

20. Goto T, Nishi T, Tamura T et al. Highly efficient electro-gene therapy of solid tumor by using an expression plasmid for the herpes simplex virus thymidine kinase gene. Proc Natl Acad Sci USA 2000; 97: 354359

21. Maruyama H, Sugawa M, Moriguchi $Y$ et al. Continuous erythropoietin delivery by muscle-targeted gene transfer using in vivo electroporation. Hum Gene Ther 2000; 11: 429-437.

22. Widera G, Austin M, Rabussay D et al. Increased DNA vaccine delivery and immunogenicity by electroporation in vivo. J Immunol 2000; 164 : 4635-4640

23. Bettan M, Emmanuel F, Darteil R et al. High-level protein secretion into blood circulation after electric pulse-mediated gene transfer into skeletal muscle. Mol Ther 2000; 2: 204-210.

24. Wells JM, Li LH, Sen A, Jahreis GP, Hui SW. Electroporation-enhanced gene delivery in mammary tumors. Gene Therapy 2000; 7: 541-547.

25. Somiari S, Glasspool-Malone J, Drabick JJ et al. Theory and in vivo application of electroporative gene delivery. Mol Ther 2000; 2: 178187.

26. Kukowska-Latallo JF, Bielinska AU, Johnson J, Spindler R, Tomalia DA, Baker JR. Efficient transfer of genetic material into mammalian cells using Starburst polyamidoamine dendrimers. Proc Natl Acad Sci USA 1996; 93: 4897-4902.

27. Kukowska-Latallo JF, Chen C, Eichman J, Bielinska AU, Baker JR Jr.
Enhancement of dendrimer-mediated transfection using synthetic lung surfactant exosurf neonatal in vitro. Biochem Biophys Res Commun 1999; 264: 253-261

28. Raczka E, Kukowska-Latallo JF, Rymaszewski M, Chen C, Baker JR Jr. The effect of synthetic surfactant exosurf on gene transfer in mouse lung in vivo. Gene Therapy 1998; 5: 1333-1339.

29. Qin L, Pahud DR, Ding Y et al. Efficient transfer of genes into murine cardiac grafts by Starburst polyamidoamine dendrimers. Hum Gene Ther 1998; 9: 553-560

30. Guillot $\mathrm{C}$, Mathieu $\mathrm{P}, \mathrm{Coathalem} \mathrm{H}$ et al. Tolerance to cardiac allografts via local and systemic mechanisms after adenovirus-mediated CTLA1lg expression. J Immunol 2000; 164: 5258-5268.

31. Suzuki J, Morishita R, Amano J, Kaneda Y, Isobe M. Decoy against nuclear factor-kappa B attenuates myocardial cell infiltration and arterial neointimal formation in murine cardiac allografts. Gene Therapy 2000; 7: 1847-1852.

32. Kawauchi M, Suzuki J, Morishita R et al. Gene therapy for attenuating cardiac allograft arteriopathy using ex vivo E2F decoy transfection by HVJ-AVE-liposome method in mice and nonhuman primates. Circ Res 2000; 87: 1063-1068.

33. Chan SY, Goodman RE, Szmuszkovicz JR, Roessler B, Eichwald EJ, Bishop DK. DNA-liposome versus adenoviral mediated gene transfer of transforming growth factor $\beta 1$ in vascularized cardiac allografts: differential sensitivity of CD4+ and CD8+ $\mathrm{T}$ cells to transforming growth factor $\beta 1$. Transplantation 2000; 70: 1292-1301.

34. Flotte $\mathrm{T}$, Agarwal $\mathrm{A}$, Wang $\mathrm{J}$ et al. Efficient ex vivo transduction of pancreatic islet cells with recombinant adeno-associated virus vectors. Diabetes 2001; 50: 515-520

35. Takehara M, Murakami M, Inobe $M$ et al. Long-term acceptance of allografts by in vivo gene transfer of regulatable adenovirus vector containing CTLA4IgG and IoxP. Hum Gene Ther 2001; 12: 415-426. 